\title{
REFLEXÕES SOBRE AS POSSIBILIDADES DE INOVAÇÃO NA RELAÇÃO PODER PÚBLICO-SOCIEDADE CIVIL NO BRASIL
}

\author{
PEDRO ROBERTO JACOBI \\ Professor da Faculdade de Educação da USP \\ Professor do Programa de Pós Graduação em \\ Ciência Ambiental da USP
}

\section{RESUMO}

Este texto aborda o tema da participação na gestão pública e as transformações qualitativas na relação Estado/Sociedade civil, enquanto referência de um ponto de inflexão e reforço das políticas públicas centradas na ampliação da cidadania ativa.

O desafio que nos colocamos é de analisar de um lado, os impactos de práticas participativas que apontam, a partir da manifestação do coletivo para uma nova qualidade de cidadania, que institui o cidadão como criador de direitos para abrir novos espaços de participação sócio-política, e de outro os aspectos que configuram as barreiras que precisam ser superadas para multiplicar iniciativas de gestão que articulam eficazmente a complexidade com a democracia.

Existe uma crescente necessidade de entender as ambiguidades dos processos sociais e os arranjos possíveis, mas principalmente os limites, tendo como referência uma análise qualitativa das práticas sociais e das atitudes dos diversos atores envolvidos, tanto nas experiências que inovam na gestão da coisa pública, como nas que mantêm inalteradas as práticas tradicionalmente desenvolvidas. 
A análise se centra em torno do fortalecimento do espaço público e na abertura da gestão pública à participação da Sociedade civil na elaboração de suas políticas públicas; e na sempre complexa e contraditória institucionalização de práticas participativas inovadoras que marcam rupturas com a dinâmica predominante, ultrapassando as ações de caráter utilitarista e clientelista.

\section{Introdução}

Este texto aborda o tema da participação na gestão pública e as transformações qualitativas na relação Estado/Sociedade civil, enquanto referência de um ponto de inflexão e reforço das políticas públicas centradas na ampliação da cidadania ativa.

Esta escolha decorre da necessidade sentida de aprofundar a reflexão em torno de um tema que, dada a sua atualidade, exige análises sobre os seus alcances e limites, mas principalmente sobre a potencialidade implícita na constituição de uma esfera pública não estatal. Isto se consubstancia através da criação de instituições voltadas para a produção e reprodução de políticas públicas que não são controladas pelo Estado, mas têm um caráter indutivo, fiscalizador e controlador sobre este.

O desafio que nos colocamos é de analisar de um lado, os impactos de práticas participativas que apontam, a partir da manifestação do coletivo para uma nova qualidade de cidadania, que institui o cidadão como criador de direitos para abrir novos espaços de participação sócio-política, e de outro os aspectos que configuram as barreiras que precisam ser superadas para multiplicar iniciativas de gestão que articulam eficazmente a complexidade com a democracia.

Observa-se que a análise das práticas participativas traz à tona, na maior parte das vezes, uma leitura que oscila entre a apologia e o voluntarismo de um lado, 
a indiferença e a subestimação, do outro; contribuindo pouco para a problematização dos complexos e diversificados processos em curso.

Existe, portanto, uma crescente necessidade de entender as ambiguidades dos processos sociais e os arranjos possíveis, mas principalmente os limites, tendo como referência uma análise qualitativa das práticas sociais e das atitudes dos diversos atores envolvidos, tanto nas experiências que inovam na gestão da coisa pública, como nas que mantêm inalteradas as práticas tradicionalmente desenvolvidas.

A análise se centra em torno do fortalecimento do espaço público e na abertura da gestão pública à participação da Sociedade civil na elaboração de suas políticas públicas; e na sempre complexa e contraditória institucionalização de práticas participativas inovadoras que marcam rupturas com a dinâmica predominante, ultrapassando as ações de caráter utilitarista e clientelista.

\section{INOVAR NA PARTICIPAÇÃO PARA UMA CIDADANIA ATIVA O DESAFIO DE SUPERAR A LÓGICA TRADICIONAL E DE CONSTRUIR UMA INSTITUCIONALIDADE}

A. Esfera pública, participação, direitos e cidadania - os atores em processo

$\mathrm{Na}$ América Latina a luta pela conquista de espaços para aumentar a participação social é sem dúvida um dos aspectos mais desafiadores para a análise sobre os alcances da democracia nas relações entre o nível local de governo e a cidadania.

Na década dos 90 a participação nas suas diversas dimensões vem sendo amparada e institucionalizada na América Latina dentro dos marcos das democracias representativas. A participação popular se transforma no referencial de ampliação das possibilidades de acesso dos setores populares dentro de uma 
perspectiva de desenvolvimento da sociedade civil $^{1}$ e de fortalecimento dos mecanismos democráticos, mas também para garantir a execução eficiente de programas de compensação social no contexto das políticas de ajuste estrutural e de liberalização da economia e de privatização do patrimônio do Estado. Entretanto, o que se observa é que no geral as propostas participativas ainda permanecem mais no plano da retórica do que na prática.

A participação minimalista (Tanaka, 1995:42-44), aponta para o fato de que existe um déficit de participação e de constituição de atores relevantes, o que pode redundar em crescente fator de crise de governabilidade ${ }^{2}$ e de legitimidade. A insatisfação pela deterioração ou a falta de melhoria nos níveis de qualidade de vida sem canais efetivos onde estes possam ser explicitados, pode conduzir à erosão da titulariedade dos atores relevantes, expressa em fenômenos como a volatilidade eleitoral e o desvirtuamento de propostas de gestão pautadas no aprofundamento das práticas democráticas.

A análise dos processos existentes está permeada pelos condicionantes da cultura política, tanto do Brasil como do resto dos países da América Latina, marcados por tradições estatistas, centralizadoras, patrimonialistas e, portanto, por padrões de relação clientelistas, meritocráticos e de interesses criados entre Sociedade e Estado. Entretanto, estes condicionantes não têm sido necessariamente um fator impeditivo para a emergência de uma diversidade de formas de participação dos setores populares, onde embora freqüentemente muitas se situem no escopo das práticas no contexto das tradições anteriormente descritas, outras as contradizem abertamente.

Assim, a participação é pensada na sua relação com o fortalecimento de práticas políticas e de constituição de direitos que transcendem os processos

\footnotetext{
${ }^{1}$ Para Hegel "a sociedade civil representa o primeiro momento de formação do Estado , o Estado jurídicoadministrativo, cuja tarefa é regular relações externas, enquanto o estado propriamente dito representa o momento ético-político, cuja tarefa é realizar a adesão íntima do cidadão à totalidade de que faz parte , tanto que poderia ser chamado de Estado interno ou interior" (Bobbio, 1987:42)

2 Adotamos o conceito sistematizado por Mello (1995:30) que qualifica o modo de uso da autoridade política formato institucional dos processos decisórios, definição do mix público/privado nas políticas, questões de participação e descentralização, mecanismos de financiamento das políticas e do escopo global dos programas (focalizados versus universalistas ).
} 
eleitorais e seus freqüentemente ambíguos e/ou contraditórios reflexos sobre a cidadania.

Nesse sentido, o tema dos direitos e da cidadania assume dimensão relevante no contexto deste referencial analítico, na medida em que permite aprofundar o significado do impacto e das transformações ocorridas na relação entre Sociedade Civil e Estado desde meados da década de 80.

No limiar do século 21, as contradições em torno do uso dos conceitos têm se acentuado, em virtude do que Santos (1996:116) entende como a continuidade do uso de uma análise "dos processos de transformação social do fim do século XX com recurso a quadros conceptuais desenvolvidos no século XIX e adequados aos processos sociais então em curso". O fortalecimento da sociedade civil coloca em xeque as criticas em torno da distinção Estado/sociedade civil ${ }^{3}$. Santos (1996:124127) refere-se a três objeções fundamentais que apresentamos a seguir: 1) parece pouco correto que se ponha em causa tal distinção precisamente no momento de reemergência da sociedade civil, levando em conta as diversidades, contraditoriedades e complexidades do processo; 2) a dificuldade de encontrar uma alternativa conceitual, enquanto prevalecer uma determinada lógica de poder ${ }^{4}$ e 3) sobretudo nas sociedades periféricas e semiperiféricas caracterizadas por uma sociedade civil fraca, pouco organizada e pouco autônoma, é politicamente perigoso pôr em causa a distinção Estado/sociedade civil.

Segundo Bobbio(1987:51) a contraposição entre as duas dinâmicas "estatalização da sociedade", mas também de "socialização do Estado" se dá "através do desenvolvimento de diversas formas de participação dentro das opções políticas, do crescimento das formas de organização de massa que exercem direta ou indiretamente algum poder político, donde a expressão Estado social pode ser entendida não só no sentido de Estado que permeou a sociedade, mas também no sentido de Estado permeado pela sociedade" . Os dois processos representam,

\footnotetext{
${ }^{3}$ Para uma reflexão aprofundada em torno dos diversos enfoques , ver Santos (1996:117-120).

${ }^{4}$ Santos (1996:127) propõe uma formulação onde a natureza político do poder não é um atributo exclusivo de uma determinada forma de poder, mas é antes o efeito global da combinação entre as diferentes formas de poder.
} 
segundo o autor, "as duas figuras do cidadão participante e do cidadão protegido que estão em conflito entre si às vezes na mesma pessoa: do cidadão que, através da participação ativa exige sempre maior proteção do Estado e através da exigência de proteção reforça aquele mesmo Estado do qual gostaria de se assenhorear e que, ao contrário, acaba por se tornar seu patrão. Sob este aspecto, sociedade e Estado atuam como dois momentos necessários, separados, mas contíguos, distintos mas interdependentes, do sistema social em sua complexidade e em sua articulação interna ".

A possibilidade de alterar a institucionalidade pública está associada às demandas que se estruturam na sociedade, e a esfera pública representa a construção da viabilidade ao exercício da influência da sociedade nas decisões públicas assim como coloca uma demanda de publicização no Estado. O que está em jogo é a necessidade de atualização dos princípios ético- políticos da democracia, onde o fortalecimento do tecido associacional potencializa 0 fortalecimento da democracia no resto das esferas da vida social. Segundo Putnam (1994) as práticas sociais que constroem cidadania representam a possibilidade de constituir-se num espaço privilegiado para cuiltivar a responsabilidade pessoal, a obrigação mútua e a cooperação voluntária. As práticas sociais que the são inerentes relacionam-se com a solidariedade, e no encontro entre direitos e deveres. A ampliação da esfera pública coloca uma demanda à sociedade em termos de obter uma maior influência sobre o Estado, tanto como sua limitação, assumindo que a autonomia social supõe transcender as assimetrias na representação social, assim como modificar as relações sociais em favor de uma maior auto-organização social (Cunill Grau, 1998:151).

B. Refletindo sobre as relações Estado e Sociedade civil no Brasil 
A redefinição das relações entre Estado e sociedade civil ${ }^{5}$ no Brasil no final dos anos 70 implica na constituição, com muitos percalços de uma esfera societária autônoma .

O surgimento da sociedade civil brasileira está indissoluvelmente vinculada não apenas à emergência de movimentos sociais, mas a um processo pelo qual atores sociais passaram a pressionar o Estado e o sistema político a se adaptarem a uma nova concepção acerca da moderna institucionalidade democrática .

Os atores sociais que emergem na sociedade civil após 1970, à revelia do Estado, criaram novos espaços e formas de participação e relacionamento com o poder público. Estes espaços foram construídos, tanto pelos movimentos populares como pelas diversas instituições da sociedade civil que articulam demandas e alianças de resistência popular e lutas pela conquista de direitos civis e sociais. Os movimentos não só tiveram papel relevante no estabelecimento de estruturas democráticas fundamentais propícias à participação popular, mas também exerceram um impacto substancial sobre as formações normativas do eleitorado e, portanto, sobre a arena política formal. Ao gerarem novos elementos de conhecimento e de cultura, muitos movimentos imprimiram sua marca e orientaram sua ação pela defesa de práticas pautadas pela sua autonomia, pela necessidade de tornar visível a sua capacidade de auto-organizar-se e de desenvolver a democracia direta, transformando as carências do seu entorno de moradia em práticas reivindicatórias. ${ }^{6}$

Outro aspecto a ser introduzido na nossa reflexão está relacionado com o fato das instituições da sociedade civil não representarem um todo monolítico,

\footnotetext{
${ }^{5}$ Para Habermas a sociedade civil constitui uma dimensão do mundo da vida assegurada institucionalmente por um conjunto de direitos que a pressupõem, ao mesmo tempo que a diferenciam das esferas da economia e do Estado (Arato e Cohen, 1994).

${ }^{6}$ Doimo (1995:47-48) desenvolve uma excelente reflexão sobre o perfil e o impacto dos movimentos e as polaridades interpretativas. Segundo a autora, três matrizes interpretativas prevaleceram desde os anos 70 . A primeira de inflexão estrutural-autonomista a partir de dois postulados - as contradições urbanas e a capacidade de organização autônoma da sociedade civil,com base na reflexão de Manuel Castells, Jordi Borja e Jean Lojkine, nos países centrais e de José A. Moisés, no Brasil . A segunda de inflexão culturalautonomista a partir de 1982 enfatizando a "pluralidade de sujeitos" e uma "constelação de novos significados" criados a partir da própria experiência através dos ensaios de Lúcio Kowarick, Eder Sader,Maria Célia Paoli ,VeraTelles, dentre os principais analistas. A terceira matriz mais conhecida como
} 
caracterizando a complexificação da sociedade e trazendo à tona as diferenças entre associações da sociedade civil e os grupos de interesse. Novos personagens entram em cena participando da esfera pública, e enfatizando a participação popular e a conquista de direitos de cidadania.

Os anos 80 trazem uma complexidade crescente nas interações dos movimentos com os órgãos públicos e uma importância maior das assessorias especializadas e das articulações interinstitucionais. A crescente politização da esfera privada, permite a construção de novos padrões de valores, configurando freqüentemente uma vinculação ideológica e política entre a necessidade e seus condicionantes estruturais. O processo de envolvimento dos moradores, e a cada vez mais freqüente resposta do poder público face às demandas, somada à participação dos profissionais e articuladores sociais e/ou assessores, possibilita a acumulação de conhecimento em torno das questões reivindicadas, vinculando-as às pautas institucionalizadas da sociedade e criando condições para a formulação de demandas junto aos órgãos públicos (Jacobi, 1990:226-228).

Deve-se destacar, também, o significado que as transformações do processo político mais amplo, provocam na feição do movimento, na medida em que estes passam a ser reconhecidos cada vez mais como interlocutores válidos. No processo de diálogo com os movimentos populares, o discurso dos órgãos públicos se transforma, incorporando paulatinamente as demandas da população dos bairros que reivindicam acesso a serviços urbanos básicos. O Estado não mais vê os movimentos somente como seus adversários, mas legitima suas reivindicações e as inscreve no campo dos direitos. Muitos movimentos apontam, a partir da reposição do coletivo, para uma qualidade diferenciada de participação na gestão da coisa pública, onde a representação não resume todo o esforço de organização, mas configura uma parte de um processo onde a população cria as condições para influenciar a dinâmica de funcionamento de um órgão do Estado. Assim, os movimentos tornam manifesta uma identidade que se concretiza a partir da construção coletiva de uma noção de direitos que, relacionada diretamente com a

"enfoque institucional" é representada dentre outros por Renato Boschi, Ruth Cardoso e Carlos Nelson dos Santos. 
ampliação do espaço de cidadania, dá lugar ao reconhecimento público das carências (Jacobi, 1990:228-229).

Com as mudanças político-institucionais que ocorrem a partir de 1983, os movimentos passam a enfrentar a tensão face à institucionalização ${ }^{7}$, configurada a partir da sua desconfiança face à participação política institucional, a defesa de um associativismo ingênuo e intransigente, assim como pelo seu visível perfil corporativista, enfatizando que esta situação decorre da ausência de critérios regulatórios que cortem transversalmente os grupos de interesse, garantindo a participação das diferenças.

A expansão do associativismo civil urbano sofre alterações desde o final dos anos 80, como resultado de dois aspectos não interdependentes: 1) a aceleração da crise econômica e 2) a perplexidade causada pela institucionalização. $\mathrm{Na}$ medida em que setores da oposição ascendem ao poder local, isto cria confusão quanto à concepção de participação. Deve, entretanto, ser registrada a multiplicidade de dinâmicas participativas nas estruturas de conselhos e colegiados criados a partir da Constituição de 1988, sendo que as agendas dos órgãos públicos contemplam crescentemente a interação com a sociedade civil. $O$ fato diferenciador destas transformações é, segundo Melucci (1994), o fortalecimento de novas instituições, as mudanças no relacionamento do quadro de pessoal com os usuários e a nova mentalidade sobre a gestão da coisa pública, enquanto aspectos constitutivos de uma nova cultura política.

Entretanto a sua crescente importância no processo político se reflete, nas diversas candidaturas progressistas vitoriosas em grandes capitais e municípios de diversos portes, na medida em que os movimentos ampliam seu espaço de inserção e conseguem também influenciar, às vezes, a agenda de gestões progressistas. Isto se verifica pela expansão do seu potencial participativo em conselhos de gestão tripartite, comissões de planejamento e outras formas específicas de representação.

\footnotetext{
${ }^{7}$ Cardoso (cf. Doimo,1995:55-56) afirma que o Estado cria a potencialidade da reivindicação e a inevitabilidade da ação direta, explicitando um potencial de conflitos que se manifesta mediante condutas de interlocução direta com o sistema de decisões .
} 
A década dos 80 , se do ponto de vista econômico representou, o que se denominou de "década perdida", no plano político consolidou um marco institucional básico de democratização. Isto demanda a necessidade de aperfeiçoamento dos instrumentos tendentes à concretização dos direitos sociais definidos na Constituição, enquanto definição de uma nova cidadania. Nos anos 90, além das práticas participativas inovadoras que se institucionalizam cada vez mais, surgem novos movimentos baseados em ações solidárias alternativas centradas em questões éticas ou de revalorização da vida humana. ${ }^{8}$

O processo de construção da cidadania é perpassado por paradoxos, na medida em que se explicitam três dinâmicas concomitantes - o reconhecimento e a construção das identidades dos distintos sujeitos sociais envolvidos, o contexto da inclusão das necessidades expressas pelos distintos sujeitos sociais e a definição de novas agendas de gestão, notadamente quanto à extensão dos bens a amplos setores da população. Esta noção de cidadania está estruturada a partir de uma definição legal dos direitos e deveres que a constituem. ${ }^{9}$

A realidade social deste fim de século apresenta um mosaico caótico, no qual também se inscreve o Brasil. A dimensão da cidadania está ancorada na participação na esfera pública. Isso inclui a participação ativa no processo público (as responsabilidades da cidadania) e nos aspectos simbólicos e éticos apoiados em fatores subjetivos que conferem um sentido de identidade e de pertencimento.

No Brasil, a reflexão em torno da cidadania ${ }^{10}$ se centra nos obstáculos à sua extensão, decorrentes da cultura política tradicional, e das perspectivas da sua transformação. A nova dimensão da cidadania inclui, de um lado, a constituição de cidadãos enquanto sujeitos sociais ativos, e de outro lado para a sociedade como um todo, um aprendizado de convivência com esses cidadãos emergentes que

\footnotetext{
${ }^{8}$ Dentre destes destaca-se A Ação da Cidadania contra a Fome, a Miséria e pela Vida . Sobre o tema ver, Jacobi (1996) que desnvolve análise sobre cinco estudos de caso.

${ }^{9}$ Há dois eixos centrais do debate ideológico, teórico e político: a natureza dos sujeito e o conteúdo dos direitos. O primeiro refere-se à visão liberal-individualista e o segundo à existência de direitos universais e a relação entre direitos humanos, civis, políticos, econômico-sociais e coletivos (Jelin, 1994:43).

${ }^{10}$ Para um aprofundamento da noção de cidadania, ver Maria V. Benevides (1991). A autora aponta o caminho da democracia semidireta como meio de recuperar a soberania popular: a associação da democracia representativa com mecanismos de democracia direta.
} 
recusam permanecer nos lugares que Ihes foram definidos social e culturalmente (Dagnino, 1994:109).

No Brasil, o modelo de gestão pública até o final da década dos setenta, estava estruturado com base na concentração do poder decisório e da execução no nível do governo federal, definindo atribuições e competências residuais para o nível estadual e definindo para os municípios atribuições de interesse local. Este processo se transforma significativamente, a partir da crise do modelo existente e das mudanças no desenho político-institucional.

A partir de $1983^{11}$ aumenta a participação dos estados e municípios nos fundos federais $^{12}$, notadamente a partir da nova Constituição promulgada em 1988 que, gradualmente aprofunda a descentralização fiscal, atribuindo-lhes ampla autonomia, não só para legislar e arrecadar tributos próprios, mas também para orçar, administrar, distender e fiscalizar seus recursos. Apesar desse processo, a estrutura legal ao não definir claramente as responsabilidades dos três níveis de governo, gera um processo desequilibrado de descentralização.

Na medida em que muitos serviços que estavam na mão da União passaram para os governos subnacionais durante a crise econômica dos 80 , a experiência recente mostra que tem ocorrido uma utilização ineficaz dos recursos ${ }^{13}$. Isto tem resultado num conjunto fragmentado e inorgânico de programas e projetos governamentais, que configuram um padrão altamente diferenciado e heterogêneo na implementação da descentralização, oscilando entre iniciativas que inovam na lógica da gestão com participação, e as que mantém as fórmulas tradicionais de clientelismo e patrimonialismo. Nessa direção um dos aspectos mais complexos e questionáveis, está relacionado com uma postura institucional de estimular a

\footnotetext{
${ }^{11}$ Nesse ano é aprovada a Emenda Passos Porto que aumenta a participação dos governos subnacionais na distribuição dos recursos tributários do país.

${ }^{12}$ Entre 1980 e 1993 verifica-se um incremento da participação dos estados de $18 \%$ e de $78 \%$ na dos municípios, enquanto a distribuição da Receita Total da União foi reduzida em 16\% (Abrucio e Couto, 1996)

13 Apesar do aumento das transferências de recursos, a ausência de garantias e de critérios claros pra os repasses de recursos vinculados às políticas sociais de forma setorializada faz com que tanto os estados como os municípios não assumam a responsabilidade pela resolução de problemas historicamente não resolvidos.
} 
participação como um fator de substituição, buscando envolver cada vez mais e de forma direta os cidadãos na produção e/ou gerenciamento dos serviços públicos.

No contexto da transição pós-democrática no Brasil e pelas pressões de uma sociedade civil mais ativa e mais organizada, foram sendo criados novos espaços públicos de interação, mas principalmente de negociação. Nesse contexto a participação citadina emerge, principalmente como referencial de rupturas e tensões, e as práticas participativas associadas a uma mudança qualitativa da gestão, assumem visibilidade pública e repercutem na sociedade.

No Brasil, o tema das políticas sociais e das desigualdades sociais deve ser analisado enquanto elemento constitutivo da cidadania de sujeitos sociais coletivos. As transformações político-institucionais e a ampliação de canais de representatividade dos setores organizados para atuarem junto aos órgãos públicos, enquanto conquista dos movimentos organizados da sociedade civil, mostram a potencialidade de construção de sujeitos sociais identificados por objetivos comuns na transformação da gestão da coisa pública, associado à construção de uma nova institucionalidade. Quando se fala de "participação dos cidadãos " deve se enfatizar que se trata de uma forma de intervenção na vida pública com uma motivação social concreta que se exerce de forma direta, baseada num certo nível de institucionalização das relações Estado/Sociedade (Jacobi, 1990:132).

O contexto da emergência de políticas públicas pautadas pelo componente participativo, está relacionado com as mudanças na matriz sócio-politica a partir de um maior questionamento sobre o papel do Estado como principal agente indutor das políticas sociais. ${ }^{14}$ A noção de participação é pensada principalmente so a ótica dos grupos interessados, e não apenas da perspectiva dos interesses globais definidos pelo Estado. O principal problema que se coloca, é de construir uma ordem societária baseada na articulação da democracia política com a participação social, representada por uma maior permeabilidade da gestão às demandas dos diversos sujeitos sociais e políticos. Essa perspectiva abre a possibilidade de

\footnotetext{
${ }^{14}$ A estrategia proposta pela CEPAL em documentos publicados nos anos 80 reconhecem a necessidade de adequar o Estado aos desafios de uma nova estratégia de inclusão nos processos sócio-politicos dos cidadãos na qualidade de cidadãos plenamente participativos (Cunill-1991).
} 
pensar a articulação entre a implantação de práticas descentralizadoras e uma engenharia institucional que concilia participação com heterogeneidade, formas mais ativas de representatividade que reforçam a reciprocidade face à dimensão de organização molecular da sociedade.

A formulação mais recorrente está estruturada em torno do aprofundamento do processo democrático, e do seu impacto na ampliação da capacidade de influência sobre os diversos processos decisórios em todos os níveis da atividade social e das instituições sociais. Nesse sentido, a participação social se caracteriza como um importante instrumento de fortalecimento da sociedade civil, notadamente dos setores mais excluídos; na medida em que a superação das carências acumuladas depende basicamente da interação entre agentes públicos e privados no marco de arranjos sócio-institucionais estratégicos. A participação social se enquadra no processo de redefinição entre o público e o privado, dentro da perspectiva de redistribuir o poder em favor dos sujeitos sociais que geralmente não tem acesso. Trata-se de pensar o ordenamento das diferenças dentro do marco de questionamento sobre o papel do Estado enquanto regulador da sociedade.

De um lado, a participação é identificada com os argumentos da democratização que têm como referência o fortalecimento dos espaços de socialização, de descentralização do poder e de crescente autonomização das decisões, portanto, enfatizando a importância de um papel mais autônomo dos sujeitos sociais. O outro enfoque aborda a participação, a partir da criação de espaços e formas de articulação do Estado com os sujeitos sociais, configurando um instrumento de socialização da política, reforçando o seu papel enquanto meio para realizar interesses e direitos sociais que demandam uma atuação pública (Cunill Grau, 1991:39-40).

C. Os desafios de pensar a participação citadina ampliada no Brasil 
A disposição de um incentivo à participação no Brasil por um número crescente de administrações municipais com perfil progressista, tem gerado reações por parte dos setores conservadores da sociedade que se mobilizam para neutralizar as possibilidades que se abrem para uma efetiva democratização nos procedimentos de gestão dos assuntos públicos. A participação se torna um meio fundamental de institucionalizar relações mais diretas e flexíveis e transparentes que reconheçam os direitos dos cidadãos; assim como de reforçar laços de solidariedade num contexto de pressão social e polarização política na direção de uma cidadania ativa que disponha dos instrumentos para o questionamento permanente da ordem estabelecida .

Para tanto é necessário que da sociedade civil surjam interlocutores coletivos - grupos comunitários, movimentos sociais, e na medida do possível, atores sociais desarticulados mas motivados ao engajamento em práticas participativas - que tornem possível uma participação ativa e representativa, sem que o Estado exija quaisquer tipos de dependência administrativa e financeira. Isto cria, portanto, as condições de romper com as práticas tradicionais - populismo, autoritarismo, clientelismo, assistencialismo, mandonismo, patrimonialismo e privatização da política nas suas diversas acepções. A participação na gestão da coisa pública, enquanto corretivo das limitações da democracia representativa, possibilita, pelo menos em tese, o engajamento da sociedade civil na formulação de políticas públicas e no controle das ações governamentais e dos negócios públicos.

A viabilização da participação deve possibilitar, apesar das limitações existentes, uma forma mais direta e cotidiana de contato entre os cidadãos e as instituições públicas, para que estas considerem os seus interesses e concepções político-sociais no processo decisório.

A importância do desenvolvimento da participação direta reside principalmente na potencial incorporação de grupos sociais e de valores sócioculturais diferentes dos que prevalecem nos organismos públicos. Entretanto, não se devem desconsiderar as contradições que podem surgir no processo, seja quanto à formação de um duplo poder, seja quanto ao controle de instâncias decisórias pelos 
grupos mais ativos e consolidados, em detrimento dos setores mais excluídos, que encontram nos mecanismos de participação direta uma primeira forma de reconhecimento dos seus interesses (Jacobi,1990:136).

Um dos maiores desafios que se coloca é o de propor alternativas às práticas de gestão, em que o peso da participação popular atue como referencial e fator de questionamento da recorrência dos problemas da administração pública face à questão dos recursos humanos. O que se verifica é que a implementação de propostas de participação, com algumas exceções, tem esbarrado numa somatória de entraves, dentre os quais se destacam a falta de agilidade nas decisões, o pouco compromisso do corpo de funcionários e, principalmente, a ausência de critérios de representação e canais administrativos que garantam o suporte institucional à interação com os grupos mais organizados e com os movimentos populares.

As mudanças qualitativas, freqüentemente emergentes do interior dos movimentos organizados da sociedade civil, assim como de propostas de governos municipais progressistas, têm geralmente encontrado uma significativa resistência dos órgãos públicos, trazendo à tona as dificuldades de implantar com efetividade estratégias participativas. Trata-se, na maioria dos casos, de resistências tecnoburocráticas, na medida em que os representantes do corpo técnico não parecem dispostos a correr riscos, temendo a influência de concepções políticoideológicas que possam vir a modificar o encaminhamento estritamente técnico dos projetos.

A participação citadina tem conotações muito diferentes, conforme sua inserção nos diversos momentos na gestão e execução das políticas. Não é a mesma coisa participar na solução de problemas, do que intervir na elaboração das opções ou das decisões de interesse público. Nesse sentido, é preciso estar atento quanto à importância de institucionalizar estas práticas, para poder avaliar qual a real capacidade de influência que os sujeitos sociais ativos têm através das diversas alternativas de participação citadina. Também torna-se da maior importância, o aprofundamento do conhecimento sobre os processos de institucionalização e como estes podem influenciar na qualidade da representação dos interesses. Referimo- 
nos ao peso quantitativo da função da representação de interesses sociais, às mediações na determinação dos representantes, ao grau de heterogeneidade dos interesses representados, ao modo de funcionamento dos órgãos e seu grau de autonomia, assim como à generalidade das funções atribuídas aos órgãos.

Trata-se de analisar as características de que se reveste a ação do Estado, na medida em que este decide sobre a legitimidade dos interesses dos grupos sociais e determina o acesso diferenciado que cada um tem aos centros decisórios; garantindo através destes meios a plena funcionalidade das instâncias participativas. Isto nos remete à reflexão em torno das formas orgânicas de participação, na medida em que o Estado é resistente à incorporação da participação ampliada. O que se observa, no geral, é que os programas participativos se restringem a uma "participação restrita ou instrumental", que não necessariamente integra uma concepção de equidade no seu arcabouço conceitual. Mais do que a distribuição dos recursos, a equidade se refere à distribuição do poder de decidir sobre a alocação dos mesmos.

As práticas participativas representam uma efetiva possibilidade de ampliação do espaço do público. Para Azevedo (1994:257) isto significa superar "a nossa tradição histórica de identificá-lo obrigatoriamente como sinônimo de governamental. Muitas vezes, em nome de supostos "interesses públicos“ mantémse estruturas e gestões estatais verticalizadas e autoritárias - não raro, focos de corrupção e malversação de verbas -, que terminam por servir de biombos para a garantia de interesses corporativos, para a privatização de recursos orçamentários e para a concessão de benefícios políticos restritos a determinados grupos e indivíduos“.

Os movimentos sociais, apesar dos argumentos em torno da sua fragmentação, dispersão e fragilidade ${ }^{15}$, ao se organizarem e demandarem direitos colocaram na agenda da democratização, segundo Avritzer e Azevedo (1994:11-12), a necessidade de compatibilização entre modernização econômico-administrativa e cidadania. Isto ocorre, na medida em que o seu impacto na constituição de uma 
arena societária em expansão Ihes permite perceber que a multiplicação de práticas democratizantes pode gerar mudanças nas suas vidas cotidianas.

O desafio maior é o de romper com a lógica clientelista que prevalece na relação Estado e sociedade. Para tanto cabe ao Estado criar espaços públicos democráticos e plurais de articulação e participação, nos quais os conflitos se tornam visíveis e as diferenças se confrontam, enquanto base constitutiva da legitimidade dos diversos interesses em questão, cedendo espaços no processo decisório e garantindo uma interação entre os grupos incluídos e o poder público, embora isto possa colidir com a dinâmica que freqüentemente preside a gestão dos serviços e sua pretensa racionalidade. Também parece necessário enfatizar que no debate em torno das políticas públicas e das estratégias de participação, corre-se sempre o risco de estabelecer relações mecânicas e utilitaristas entre discurso e ação.

Entretanto, a participação tem limites, isto significando que a panacéia participativa não é o mecanismo que responda satisfatoriamente, nem a todos os problemas dos moradores excluídos que demandam acesso aos serviços públicos; nem aos grupos sociais que, satisfeitas as necessidades básicas, se engajam enquanto sujeitos de uma organização política e de atos públicos que afetam a vida de todos. A alternativa da participação representa, tanto a possibilidade concreta de se criar condições para acrescentar equanimidade na distribuição dos recursos públicos, como estabelecer regras de reciprocidade e de transformação sociocultural na dinâmica assimétrica que caracteriza as relações Estado e sociedade, apontando para reforçar a existência de sujeitos-cidadãos que demandam um processamento político das suas demandas globais, como também se integram no processo de influenciar diretamente na definição de diretrizes e na formulação de políticas públicas.

A consolidação de propostas participativas, representa a potencialização e a ampliação de práticas comunitárias, através do estabelecimento e ativação de um conjunto de mecanismos institucionais que reconheçam direitos efetivamente

\footnotetext{
${ }^{15}$ No livro de Doimo (1995:46-53) estão sistematizados os principais argumentos desenvolvidos nessa linha de
} 
exercíveis e estimulem estratégias de envolvimento e co-responsabilização. Nesse sentido, um dos maiores desafios de uma proposta participativa ampliada é o de garantir a definição de critérios de representação, de forma a impedir, tanto a sua manipulação por grupos guiados por interesses particularizados, assim como a possibilidade da sua instrumentalização pela administração pública.

\section{GEStÃo PÚblicA E ENGAJAMENTO DA SOCIEDADE CIVIL NO PROCESSO DECISÓRIO NO BRASIL}

A análise de experiências brasileiras mostra o desafio que se coloca para garantir a eficácia e continuidade de políticas públicas de caráter progressista, é de reforçar os meios para envolver e manter o interesse da população e dimensionar adequadamente os arranjos institucionais. A sua descontinuidade reforça o argumento, que gestão democrática e participação popular requerem uma forma combinada de fortalecimento das formas de organização da sociedade civil, uma mudança na correlação de forças, uma transformação qualitativa dos padrões de gestão, enfim, um processo real de democratização do Estado e da sua gestão. Esta transformação requer o que Arato e Cohen (1994) definem como a existência de uma sociedade civil organizada, diferenciada e adequadamente defendida, capaz de influenciar o Estado e que tem condições de garantir a manutenção de direitos essenciais e de monitorar e influenciar os processos que se regulam pela lógica sistémica. Mas também mostra que os processos são lentos, e não necessariamente unidirecionais.

O complexo processo de construção da cidadania no Brasil num contexto de agudização das desigualdades, é perpassado por um conjunto de questões que necessariamente implicam, na superação das bases constitutivas das formas de 
dominação e de uma cultura política baseada na tutela, no clientelismo e no patrimonialismo político. O desafio da construção de uma cidadania ativa, se configura como elemento determinante para a consolidação de sujeitos-cidadãos, que portadores de direitos e deveres, assumem a sua conviccão pela abertura de novos espaços de participação, enquanto componente essencial de ruptura com a lógica que os faz permanecerem excluídos e dependentes das fórmulas tradicionais que prevalecem na vida política brasileira.

A constituição de cidadãos, enquanto sujeitos sociais ativos, se consubstancia a partir da transformação das práticas sociais existentes e na sua substituição pela construção de novas formas de relação, que tem na participação um componente essencial. O enfrentamento do patrimonialismo político é uma tarefa complexa e demorada em virtude do enraizamento das práticas de instrumentalização. O desafio que se coloca é o de construir novos hábitos, de neutralizar o clientelismo e de aproximar o cidadão do processo decisório.

A participação da sociedade civil na gestão pública introduz uma mudança qualitativa na medida em que incorpora outros níveis de poder além do Estado. Isto se configura como um direito ao auto-desenvolvimento que pode ser alcançado numa sociedade participativa que contribui para a formação de uma cidadania qualificada.

A efetiva participação da população nos processos decisórios, como é o caso Orçamento do Participativo ${ }^{16}$, que vem se constituindo como um mecanismo ampliado de engajamento da sociedade na gestão das políticas públicas, requer um esforço crescente de institucionalização da possibilidade de atendimento das demandas em bases negociadas. Trata-se de processar demandas e pressões e de implementar mecanismos formais que contemplem, tanto os setores organizados e mobilizados estimulando sua adequação à institucionalidade respeitando a

\footnotetext{
${ }^{16} \mathrm{O}$ Orçamento Participativo foi criado no primeiro ano de governo e desde o início existiu uma preocupação da Administração em articular e compensar tanto os objetivos-carências como os aspectos marcados pela subjetividade que é inerente a um processo participativo. O regulamento é uma peça central porque inibe as práticas clientelistas. A implantação foi muito difícil, notadamente pela falta de recursos para investimento. A partir de 1989/90, com base numa profunda reforma tributária concomitante a outras medidas de saneamento financeiro, verifica-se um fortalecimento do processo. Atualmente o processo está legitimado e consta da agenda pública como mola propulsora do processo decisório da ação governamental (Jacobi,1996: 3-6).
} 
autonomia e a auto-organização, como de envolvimento dos setores desorganizados. Isto está sendo construído dentro de uma lógica que não está apenas permeada pelo imediatismo e o utilitarismo, mas por uma radicalização da democracia que alargando os direitos de cidadania no plano político e social constrói efetivamente novas relações entre governantes e governados. Este processo de gestão através do ingresso da cidadania organizada na máquina do Estado, possibilita conhecer seu funcionamento e seus limites e estimula a construção de uma relação de co-responsabilização e de disputa, visando produzir consensos cada vez mais qualificados.

A experiência do Orçamento Participativo em Porto Alegre ${ }^{17}$ está diretamente vinculada com a capacidade que a administração local tem de criar canais legítimos de participação, combinando elementos da democracia representativa e de democracia participativa. Trata-se de uma experiência que tem se multiplicado, enquanto referência da adoção de um processo participativo, baseado no conceito de esfera pública não estatal ${ }^{18}$ que incide sobre o Estado, com ou sem o suporte da representação política tradicional. Esta é constituída por uma multiplicidade de organizações sociais, admitindo de acordo com Genro (1996:5/3) “ a tensão política como método decisório e dissolvendo o autoritarismo do Estado tradicional sob pressão da sociedade organizada". Nesse contexto, a participação adquire uma linguagem e uma prática de ruptura com 0 corporativismo territorialmente determinado, com ênfase numa lógica presidida por uma abordagem universal da cidade $^{19}$, criando para os setores populares, segundo Avritzer e Azevedo (1994:26), "uma opção viável e altamente competitiva de participação política alternativa às práticas clientelistas". O Orçamento Participativo representa a possibilidade do Poder Público ser o indutor de uma ampliação do espaço público que se caracteriza pela mudança do comportamento político com uma redução das práticas

\footnotetext{
${ }^{17}$ Segundo Utzig (1996:215) o Orçamento Participativo é uma estrutura autônoma e auto-regulada, sendo que suas normas de funcionamento foram definidas pela própria comunidade através do Conselho Municipal do Orçamento Participativo e com independência do executivo e do legislativo.

${ }^{18} \mathrm{O}$ governo é um ator relevante no processo, entretanto opera segundo regras que a comunidade define e que ele aceita através de um pacto político (Utzig,1996:215).

19 A distribuição das obras emerge de uma relação contratual previamente estabelecida, através de um regulamento que determina as regras básicas de negociaçào interna de cada região da cidade e entre regiões, dificultando o clientelismo ( Jacobi e Teixeira, 1996: 24).
} 
clientelistas. Para Navarro (1999: 320-321) parecem existir sinais de que um imaginário democrático começa a se constituir na cidade de Porto Alegre, principalmente entre os setores de renda mais baixa. Assim "uma vez que o nível de investimentos não possibilita resolver todos os problemas sociais e atender todas as demandas, aprender como participar e negociar com outros grupos é uma necessidade inevitável. Se um conjunto de regras acordado depois de intensas discussões ( possuindo assim legitimidade definitiva) governa todo o processo, e se - espaço para manobras clientelistas está diminuindo, então não há outra opção senão integrar-se ao processo e tentar obter êxito no mesmo" (Navarro, 1999: 321). A experiência mostra a necessidade de articular três dinâmicas: a mobilização mais ampla possível, a transformação da burocracia e a constituição de apoio político (Abers, 1998). O aprendizado político fortalece práticas de combate às posturas utilitaristas adotadas pelas organizações comunitárias, e que se traduzem na competição por recursos escassos, e práticas autoritárias e clientelisticas que são comuns até mesmo entre os próprios líderes comunitários, como revelam pesquisas realizadas nos primeiros anos da implementação do Orçamento Participativo. ${ }^{20}$ Mas, apesar da sua repercussão positiva, também devem ser mostrados os seus limites, e estes residem, segundo os analistas, nas contradições associadas às dificuldades de ampliar a participação e a dependência em relação às autoridades municipais para estruturar a dinâmica de funcionamento (Navarro, 1999: 332).

As transformações político-institucionais aqui apresentadas, abrem um estimulante espaço para a construção de uma nova institucionalidade que tem na participação um componente importante para o fortalecimento da oferta citadina na gestão da coisa pública, concordando com a afirmação de Navarro(1999:320) que “ a noção de representação tem-se afirmado gradualmente em muitas regiões da cidade como valor social".

As dimensões diferenciadas de participação mostram a necessidade de superar ou conviver com certos condicionantes sócio-políticos e culturais, na medida em que o salto qualitativo começa a ocorrer a partir de diferentes engenharias

\footnotetext{
${ }^{20}$ Uma descrição detalhada do Orçamento Participativo em Porto Alegre é apresentada no livro -Orçamento Participativo - de autoria de Tasso Genro e Ubiratan de Souza, Editora Fundação Perseu Abramo, São Paulo,
} 
institucionais que "tem uma progressiva penetração de formas públicas de negociação dentro da lógica da administração pública, renovando os potenciais do exercício da democracia" (Avritzer e Azevedo, 1994:28). Isto também reforça a importância de pensar a participação como um método de governo (Borja,1988) que pressupõe a realização de certas pré-condições necessárias à sua viabilização no nível do possível, dadas as características da cultura política brasileira.

Os complexos e desiguais avanços revelam que estas engenharias institucionais, baseadas na criação de condições efetivas para multiplicar experiências de gestão participativa que reforçam o significado da publicização das formas de decisão e de consolidação de espaços públicos democráticos, ocorrem pela superação das assimetrias de informação e pela afirmação de uma nova cultura de direitos. Estas experiências, que denominamos inovadoras, fortalecem a capacidade de crítica e de interveniência dos setores de baixa renda, através de um processo pedagógico e informativo de base relacional, assim como a capacidade de multiplicação e aproveitamento do potencial dos cidadãos no processo decisório dentro de uma lógica não cooptativa. Isto mostra que existem condições favoráveis para cidadanizar a política, deslocando seu eixo do âmbito estatal para o cidadão (Cunill Grau, 1998: 177).

Entretanto, estas experiências que inovam na relação entre Estado e Sociedade civil ainda estão longe de representar um paradigma de significativa repercussão no atual quadro brasileiro, principalmente em virtude da falta de vontade política dos governantes e da fragilidade do tecido associativo. Os grupos organizados que interagem e pressionam, representam iniciativas fragmentárias que não atingem o cerne de uma sociedade refratária a práticas coletivas. ${ }^{21} \mathrm{~A}$ realidade brasileira é marcada por configurar um contexto de baixa institucionalização onde a maioria da população pouco se mobiliza para explicitar sua disposição de utilizar os instrumentos da democracia participativa visando romper com o autoritarismo social que prevalece, além do fato da maioria das organizações sociais serem ou

${ }^{21}$ Santos (1993) desenvolve uma provocante reflexão ( notadamente no capítulo III - Fronteiras do Estado Mínimo) sobre as mazelas da cultura política brasileira e as barreiras auma participação mais ativa . 
relativamente frágeis ou extremamente especializadas, tendendo a estabelecer relações particularizadas e diretas com a administração pública local.

A resposta a esta questão se torna ainda mais complexa na medida em que tomamos como uma referência possível e contraditória a pesquisa sobre as práticas sociais face aos problemas ambientais na cidade de São Paulo. Os resultados mostram que mais de $80 \%$ dos moradores de São Paulo, quando consultados sobre o meio de ação mais efetivo para resolver os problemas ambientais no nível domiciliar e do bairro indicam a ação governamental, sendo que a opção pela ação comunitária é quase sete vezes menor. Isto abre um estimulante campo de reflexão. Cabe, entretanto, ressaltar que as respostas enfatizam a importância do poder público exercer um papel nucleador e estruturador das ações no desempenho da função de informar e orientar através de campanhas educativas; fiscalizar e monitorar a execução de políticas públicas; e estimular uma dinâmica de coresponsabilização da comunidade na prevenção da desordem e degradação ambiental, configurando a existência de um potencial de oferta citadina orientada para uma atuação mais orientada para a defesa do interesse geral.

Os desafios para ampliar a participação estão intrinsecamente vinculados à predisposição dos governos locais de criar espaços públicos e plurais de articulação e participação, nos quais os conflitos se tornam visíveis e as diferenças se confrontam, enquanto base constitutiva da legitimidade dos diversos interesses em jogo. Isto nos remete à necessidade de ter como referência, não só suficiente mas necessária, uma engenharia institucional legítima aos olhos da população, que garanta espaços participativos transparentes e pluralistas numa perspectiva de busca de equidade e justiça social configurada pela articulação entre complexidade administrativa e democracia 
O que as diversas experiências de gestão municipal mostram é que a ampliação da cidadania está associada a uma proposta de garantia da governabilidade, como atestam as reeleições em prefeituras progressistas. ${ }^{22}$

${ }^{22}$ No ano de 1992, onze prefeituras administradas pelo PT foram reeleitas, dentre as quais Porto Alegre e 
A experiência brasileira, na sua especificidade, traz à tona as ambigüidades e as possibilidades que se colocam para uma atuação cada vez mais democrática de um Estado centrado, tanto na garantia da qualidade de vida, quanto da ampliação dos direitos de cidadania. A questão que se coloca é sobre o papel do Estado enquanto agente de controle ou participação, notadamente quanto à criação de um ambiente facilitador - capacidade de mobilizar energias e recursos da sociedade, estimulando diversos tipos de parcerias público/privado - e de garantir implantação de políticas que privilegiam um estreito relacionamento entre eqüidade e participação. O pressuposto desta abordagem é a possibilidade de pensar a sociedade civil na busca de superação de uma participação minimalista assumindo uma nova dimensão configurada, segundo Avritzer e Azevedo (1994:5) "na possibilidade de se transformar aquilo que é uma indissociável tensão numa relação produtiva". As possibilidades de reverter de forma significativa o atual quadro estão associadas, de um lado à necessidade de uma reinvenção solidária e participativa do Estado, parafraseando Boaventura de Souza Santos. De outro, na difícil tarefa das organizações da sociedade civil, num contexto de erosão de direitos, de consolidar práticas que fortaleçam a sua capacidade de interlocução na definição de políticas públicas e na partilha dos recursos provenientes dos fundos públicos.

A participação deve ser entendida como um processo continuado de democratização da vida municipal, forma de intervenção na vida pública com uma motivação social concreta que se exerce de forma direta, e método de governo centrado na institucionalização das relações entre o Estado e a sociedade civil. Entretanto a participação tem limites e isto significa que a " panacéia participativa" não é o mecanismo que solucione todos os problemas dos moradores excluídos do acesso aos serviços públicos, mas uma possibilidade concreta de se criar condições para atingir uma eqüanimidade na sua distribuição (Jacobi,1990). É importante ressaltar, que as experiências apresentadas explicitam a existência/inexistência de um potencial de ruptura em torno da distância quase sempre presente entre o poder centralizado e as realidades sociais mutantes e heterogêneas. Isto põe em evidência os limites dos mecanismos existentes formais, verticais, corporativos e clientelistas, construídos para permitir/impedir a 
participação dos cidadãos nos assuntos públicos. Estes limites foram mantidos/superados pelas administrações municipais progressistas, que assumiram o risco calculado de abrir canais de interação com os movimentos sociais organizados e os novos atores políticos que questionam práticas tuteladas, e buscam consolidar de forma partilhada novas formas de representação, organização e cooperação. Nesse sentido, e face à extrema urgência no atendimento às múltiplas demandas sociais dos setores mais excluidos, a participação se fortalece através do estímulo às práticas dialógicas permanentes, baseadas em regras de reciprocidade e de transformação sócio-cultural na dinâmica assimétrica que caracteriza as relações entre Estado e Sociedade .

A alternativa da participação deve ser vista pela ótica dos níveis de concessão dos espaços de poder e, portanto, pela sua maior ou menor ruptura com estruturas tradicionais, patrimonialistas e autoritárias. Isto configura a possibilidade dos cidadãos assumirem um papel relevante no processo de dinamização da sociedade, assim como de reforçar o exercício de um controle mais permanente e consistente dos usuários na gestão da coisa pública, sustentado no acesso à informação a todos os grupos sociais sobre o funcionamento do governo da cidade.

A superação das barreiras sócio-institucionais é o caminho para a efetiva democratização da gestão e o estímulo à co-responsabilização na defesa do interesse geral. Nesse sentido o crescimento da experiência de cidadania ativa aquela que institui o cidadão como portador de direitos e deveres, mas essencialmente criador de direitos para abrir novos espaços de participação, aponta para a importância da educação para a cidadania enquanto meio de transformar constantemente a capacidade de engajamento sócio-político dos atores sociais relevantes.

A educação para a cidadania representa a possibilidade de motivar e sensibilizar as pessoas para transformar as diversas formas de participação em potenciais fatores de dinamização da sociedade e de ampliação do controle social da coisa pública, inclusive pelos setores menos mobilizados. Trata-se de criar as condições para a ruptura com a cultura política dominante e para uma nova proposta 
de sociabilidade baseada na educação para a participação, Esta se concretizara principalmente pela presença crescente de uma pluralidade de atores que, através da ativação do seu potencial de participação terão cada vez mais condições de intervir consistentemente e sem tutela nos processos decisórios de interesse público, legitimando e consolidando propostas de gestão baseadas na garantia do acesso à informação, e na consolidação de canais abertos para a participação que, por sua vez, são pré-condições básicas para a institucionalização do controle social. 


\section{BIBLIOGRAFIA}

ABERS, R. 1998.- " Learning Democratic Practice: Distributing Government Resources through Popular Participation in Porto Alegre, Brazil ". DOUGLASS, M. and FRIEDMANN, J. (orgs.) Cities for Citizens. John Wiley and Sons, New York.

ARATO, A. e COHEN, J. 1994.- "Sociedade civil e teoria social " in: AVRITZER,L. Sociedade civil e Democratização. Del Rey, Belo Horizonte.

AVRITZER, L. e AZEVEDO, S. 1994.- A política do Orçamento Participativo Formas de relacionamento entre Estado e sociedade civil. XVII Encontro Anual da ANPOCS, Caxambu, Minas Gerais, mimeo, 30 pp.

AZEVEDO, S. 1994.- "Planejamento, cidade e democracia: reflexões sobre o papel dos governos locais nos anos 90": 244-270. DINIZ, E.; LOPES, J.S. e PRANDI, R. (orgs.). O Brasil no Rastro da Crise. ANPOCS/Hucitec, São Paulo.

BOBBIO, N. 1987.- Estado, Governo, Sociedade. Paz e Terra, São Paulo.

BORJA, J. 1988.- Estado y Ciudad. PPU, Barcelona.

BRESSER PEREIRA, L.C. e CUNILL GRAU, N. (orgs.) 1999. O Público Não- Estatal na Reforma do Estado. Editora da Fundação Getúlio Vargas/CLAD. Rio de Janeiro.

CUNNILL GRAU, N. 1991. - Participación Ciudadana. CLAD, Caracas.

CUNILL GRAU, N. 1998. Repensando o público através da sociedade. Editora Revan/ENAP. Rio de Janeiro.

DAGNINO, E. 1994.- " Os movimentos sociais e a emergência de uma nova noção de cidadania":103-118. DAGNINO, E. (org.) Política e Sociedade no Brasil. Editora Brasiliense, São Paulo. 
JACOBI, P. 1990.- "Descentralização Municipal e Participação dos cidadãos: apontamentos para o debate". Revista LUA NOVA, vol 20:121-144. CEDEC, São Paulo.

JACOBI, P. 1991.- "Políticas Públicas e Alternativas de Inovação da Gestão Municipal: o complexo caso da cidade de São Paulo". Cadernos CEDEC vol.18. CEDEC, São Paulo.

JACOBI, P. 1994.- "Alcances e limites de governos locais progressistas no Brasil: as prefeituras petistas". Cadernos do CEAS, vol. 152:11-31. CEAS, Salvador.

JACOBI, P. 1995.- "Moradores e Meio Ambiente e São Paulo":133-169. A Questão Ambiental:cenários de pesquisa. NEPAM/UNICAMP, Campinas.

JACOBI, P. E TEIXEIRA, M.A. 1996.- Orçamento Participativo: o caso de São Paulo (1989-1992), à luz das experiências de Porto Alegre e Belo Horizonte. CEDEC, São Paulo, mimeo, 31 pp.

MELUCCI, A. 1994.- "Movimentos sociais, renovação cultural e o papel do conhecimento". Entrevista feita por Avritzer, L. e Lyyra, T. Revista Novos Estudos CEBRAP, vol. 40:152-166. CEBRAP, São Paulo.

NAVARRO, Z. 1999.- "Democracia e controle social de fundos públicos- o caso do "orçamento participativo" de Porto Alegre (Brasil)":293-334. BRESSER PEREIRA, L.C. e CUNILL GRAU (orgs.). O Público Não-Estatal na Reforma do Estado. Editora da Fundação Getulio Vargas/CLAD, Rio de Janeiro.

PUTNAM, R. 1994. Making Democracy Work. Princeton University Press, New Jersey.

SANTOS, B. 1996.- Pela Mão De Alice. Cortez Editora, São Paulo.

TANAKA, M. 1995. -" La participación politica de los sectores populares en América Latina". Revista Mexicana de Sociologia, vol.3:41-66, Mexico. 
TELLES, V.1994.- "Sociedade civil e a construção de espaços públicos": 91-102, in:

DAGNINO, E. (org.) Anos 90: Política e Sociedade no Brasil. Editora Brasiliense, São Paulo.

WOLFE, A. e STIEFEL, M. 1994.- $A$ Voice for the Excluded-Popular Participation in Development : Utopia or Necessity? UNRISD/Zen Books, Londres.

WOLFE, M. 1991.- "Las múltiplas facetas de la participación". Revista Pensamiento Iberoamericano, vol 19: 352-361. ICLCEPAL, Madrid. 